

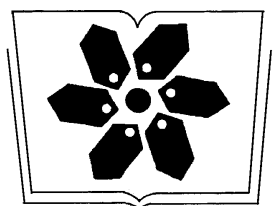

中国科学院科学出版基金资助出版
生态学 报

(SHENGTAI XUEBAO)

第 33 卷第 13 期 2013 年 7 月 (半月刊)

\section{前沿理论与学科综述}

\section{目次}

强度千扰后退化森林生态系统中保留木的生态效应研究综述.

AM 真菌对重金属污染土壤生物修复的应用与机理

\section{个体与基础生态}

东灵山不同林型五角枫叶性状异速生长关系随发育阶段的变化 不同温度下 $\mathrm{CO}_{2}$ 浓度增高对坛紫菜生长和叶绿素荧光特性的影响 基于 LULUCF 温室气体清单编制的浙江省杉木林生物量换算因子. 土壤逐渐千旱对菖蒲生长及光合荧光特性的影响. …

一株柠条内生解磷菌的分离鉴定及实时荧光定量 PCR 检测 一个年龄序列巨桉人工林植物和土壤生物多样性 不同饵料和饥饿对鬼蚶幼虫生长和存活的影响 禽畜养殖粪便中多重抗生素抗性细菌研究…… 链状亚历山大藻赤潮衰亡的生理调控 基于环境流体动力学模型的浅水草藻型湖泊水质数值模拟 种群、群落和生态系统

千旱半千旱地区围栏封育对甘草群落特征及其分布格局的影响 宁夏六盘山三种针叶林初级净生产力年际变化及其气象因子响应 半千旱黄土区成熟柠条林地土壤水分利用及平衡特征. 模拟酸沉降对鼎湖山季风常绿阔叶林地表径流水化学特征的影响........ 基于改进 PSO 的洞庭湖水源涵养林空间优化模型 外来植物火炬树水浸液对土壤微生态系统的化感作用 崇明东滩抛荒鱼塘的自然演替过程对水乌群落的影响 三峡水库蓄水初期鱼体永含量及其水生食物链累积特征 元江鲤种群遗传多样性

\section{景观、区域和全球生态}

中国西北干旱区气温时空变化特征 黄 荵, 徐利岗, 刘俊民 (4078) 集水区尺度下东北东部森林土壤呼吸的模拟 郭丽娟, 国庆喜 (4090) 增氮对青藏高原东缘高寒草甸土壤甲烷吸收的早期影响 张裴雷,方华军, 程淑兰, 等 (4101) 基于生态系统服务的广西水生态足迹分析 张义，张合平 深圳市景观生态安全格局源地综合识别 吴健生, 张理卿, 彭 建, 等 
庐山风景区碳源、碳汇的测度及均衡. 周年兴, 黄震方, 梁艳艳 (4134)

气候变化对内蒙古中部草原优势牧草生长季的影响 李夏子, 韩国栋, 郭春燕

民勤荒漠区典型草本植物马荡的物候特征及其对气候变化的响应. 韩福贵,徐先英, 王理德, 等 (4156)

血水草生物量及碳咜量分布格局

田大伦, 间文德, 梁小翠, 等

5 种温带森林生态系统细根的时间动态及其影响因子 李向飞,王传宽,全先奎

\section{资源与产业生态}

千旱胁迫下 AM 真菌对矿区土壤改良与玉米生长的影响 李少朋, 毕银丽, 陈昢圳, 等

\section{城乡与社会生态}

上海环城林带保健功能评价及其机制

张凯旋, 张建华 (4189)

\section{研究简报}

北京山区侧柏林林内降雨的时滞效应 史宇,余新晓, 张佳音

采伐剩余物管理措施对二代杉木人工林土壤全碳、全氮含量的长期效应

胡振宏, 何宗明, 范少辉, 等 (4205)

期刊基本参数: CN 11-2031/Q * 1981* m * 16*326* zh *P* ¥90.00*1510*35*2013-07

封面图说: 岳阳附近的水源涵养林及水系鸟瞰——水源涵养林对于调节径流,减缓水、旱灾害,合理开发利用水资源具有重要 的生态意义。洞庭湖为我国第二大淡水湖,南纳湘、资、沅、澧四水,北由岳阳城陵矶注人长江, 是长江上最重要的水 量调节湖泊。因此,湖周的水源涵养林建设对于恢复洞庭湖调节长江中游地区洪水的功能,加强湖区生物多样性的 保护是最为重要的举措之一。对现有防护林采取人为干扰的调控措施,改善林分空间结构,将有利于促进森林生态 系统的正向演替, 为最大程度恢复洞庭湖水源林生态功能和健康经营提供重要支撑。

彩图及图说提供: 陈建伟教授 北京林业大学 E-mail：cites.chenjw@163.com 


\title{
5 种温带森林生态系统细根的时间动态及其影响因子
}

\author{
李向飞, 王传宽 ${ }^{*}$, 全先奎 \\ ( 东北林业大学生态研究中心, 哈尔滨 150040 )
}

摘要: 细根 (直径 $\leqslant 2 \mathrm{~mm}$ ) 的生长和死亡动态及其影响因子是森林生态系统能量流动和物质循环的重要研究内容, 但因受到研 究方法的限制而了解甚少。于 2010 年 5-10 月采用微根管技术对东北东部山区 5 种温带森林生态系统的细根生长量 (FRP) 和死亡量 $(\mathrm{FRM})$ 进行了动态跟踪测定, 并同步测定了土壤温度 $(T \mathrm{~s})$ 、土壤湿度 $(M \mathrm{~s})$ 、叶面积指数 $(\mathrm{LAI})$ 等相关因子。结果表 明: 不同林型和取样时间的 FRP 和 FRM 均差异显著 $(P<0.001)$ 。杨华林、硬阔叶林、兴安落叶松林、红松林、蒙古柇林的 FRP 和 FRM 分别为: $(13.34 \pm 0.90) \mu \mathrm{m} \cdot \mathrm{cm}^{-2} \cdot \mathrm{d}^{-1}$ (平均值士标准误) 和 $(5.02 \pm 0.36) \mu \mathrm{m} \cdot \mathrm{cm}^{-2} \cdot \mathrm{d}^{-1} 、(13.04 \pm 0.82) \mu \mathrm{m} \cdot \mathrm{cm}^{-2} \cdot \mathrm{d}^{-1}$ 和 $(6.85 \pm$ $0.32) \mu \mathrm{m} \cdot \mathrm{cm}^{-2} \cdot \mathrm{d}^{-1} 、(8.74 \pm 1.44) \mu \mathrm{m} \cdot \mathrm{cm}^{-2} \cdot \mathrm{d}^{-1}$ 和 $(5.05 \pm 0.61) \mu \mathrm{m} \cdot \mathrm{cm}^{-2} \cdot \mathrm{d}^{-1} 、(8.02 \pm 2.27) \mu \mathrm{m} \cdot \mathrm{cm}^{-2} \cdot \mathrm{d}^{-1}$ 和 $(3.88 \pm 0.35)$ $\mu \mathrm{m} \cdot \mathrm{cm}^{-2} \cdot \mathrm{d}^{-1} 、(7.59 \pm 0.82) \mu \mathrm{m} \cdot \mathrm{cm}^{-2} \cdot \mathrm{d}^{-1}$ 和 $(3.88 \pm 0.61) \mu \mathrm{m} \cdot \mathrm{cm}^{-2} \cdot \mathrm{d}^{-1}$ 。所有林型生长季期间 FRP 的时间变化均呈现明显 的单峰型, 但峰值出现的时间却因林型而异。FRM 随生长季的进程而逐渐增加, 杨桦林和硬阔叶林 FRM 在 8 月初出现峰值, 而 红松林、兴安落叶松林和蒙古柇林的 FRM 峰值均出现在生长季末期。 $T \mathrm{~s} 、 M \mathrm{~s}$ 和 LAI 对 FRP 和 FRM 均存在显著的正效应 $(P<$ 0.05), 3 个因子的综合作用对各个林型 FRP 和 FRM 变异性的解释率分别达 $68 \%$ 和 $53 \%$ 以上, 表明这些温带森林生态系统细 根生长和死亡的时间动态主要受土壤温湿度和叶面积变化的联合影响。

关键词: 细根生长量; 细根死亡量; 季节动态; 土壤温度; 土壤湿度; 叶面积指数

\section{Temporal dynamics and influencing factors of fine roots in five Chinese temperate forest ecosystems}

\author{
LI Xiangfei, WANG Chuankuan* , QUAN Xiankui \\ Center for Ecological Research, Northeast Forestry University, Harbin 150040, China
}

\begin{abstract}
Production and mortality of fine roots (diameter $\leqslant 2 \mathrm{~mm}$ ) and influencing factors are important to energy flow and nutrient cycling in forest ecosystems, but remain poorly understood mainly due to the limitation of methodology. In this study, we used a minirhizotron technique to investigate the temporal dynamics in fine root length production ( FRP) and mortality (FRM) of five representative forest ecosystems in Northeast China during the period between May and October of 2010. Soil temperature $\left(T_{\mathrm{s}}\right)$, soil moisture $\left(M_{\mathrm{s}}\right)$, and leaf area index $(\mathrm{LAI})$ were simultaneously measured for each stand. The stands were aspen-birch forest dominated by Populus davidiana and Betula platyphylla, hardwood forest dominated by Fraxinus mandshurica and Juglans mandshurica, Mongolian oak forest dominated by Quercus mongolica, Korean pine (Pinus Koraiensis) plantation, and Dahurian larch (Larix gmelinii) plantation. The experimental design included five forest types, three $20 \mathrm{~m} \times 30 \mathrm{~m}$ replicate plots in each forest type. The results showed that the FRP and FRM were significantly $(P<0.001)$ affected by forest types, sampling times and their interactions. The FRP was $(13.34 \pm 0.90)$ $\mu \mathrm{m} \cdot \mathrm{cm}^{-2} \cdot \mathrm{d}^{-1}($ mean $\pm \mathrm{SE}),(13.04 \pm 0.82) \mu \mathrm{m} \cdot \mathrm{cm}^{-2} \cdot \mathrm{d}^{-1},(8.74 \pm 1.14) \mu \mathrm{m} \cdot \mathrm{cm}^{-2} \cdot \mathrm{d}^{-1},(8.02 \pm 2.77) \mu \mathrm{m} \cdot \mathrm{cm}^{-2} \cdot \mathrm{d}^{-1}$,
\end{abstract}

基金项目:国家“十二五”科技支撑项目(2011BAD37B01); 教育部长江学者和创新团队发展计划( IRT1054); 国家林业局重点项目(2006-77)

收稿日期:2012-12-04; 修订日期:2013-04-18

* 通讯作者 Corresponding author. E-mail: wangck-cf@ nefu. edu. cn 
and $(7.59 \pm 0.82) \mu \mathrm{m} \cdot \mathrm{cm}^{-2} \cdot \mathrm{d}^{-1}$ for the aspen-birch, hardwood, larch, pine, and oak stands, respectively; and the FRM was $(5.02 \pm 0.36) \mu \mathrm{m} \cdot \mathrm{cm}^{-2} \cdot \mathrm{d}^{-1},(6.85 \pm 0.32) \mu \mathrm{m} \cdot \mathrm{cm}^{-2} \cdot \mathrm{d}^{-1},(5.05 \pm 0.61) \mu \mathrm{m} \cdot \mathrm{cm}^{-2} \cdot \mathrm{d}^{-1},(3.88 \pm 0.35) \mu \mathrm{m} \cdot$ $\mathrm{cm}^{-2} \cdot \mathrm{d}^{-1}$, and $(3.88 \pm 0.61) \mu \mathrm{m} \cdot \mathrm{cm}^{-2} \cdot \mathrm{d}^{-1}$, correspondingly. The FRP showed a unimodal seasonal pattern with peaks varying with forest types. The FRM increased gradually as the growing season proceeded, and reached its maximum at the end of the growing season for all the stands except for the aspen-birch and hardwood stands where it peaked in early August. $T \mathrm{~s}, M \mathrm{~s}$, and LAI all exerted significant positive effects on FRP and FRM $(P<0.05)$, which, together, explained more than $68 \%$ and $53 \%$ of variability in FRP and FRM, respectively. These results illustrated that the temporal dynamics of fine root production and mortality in these temperate forest ecosystems were jointly influenced by changes in soil temperature, moisture and leaf area index.

Key Words : fine root production; fine root mortality; seasonality; soil temperature; soil moisture; leaf area index

细根 (直径 $\leqslant 2 \mathrm{~mm}$ ) 是植物吸收养分和水分的主要器官, 其生产和周转构成了森林生态系统物质循环和 能量流动的重要部分 ${ }^{[1]}$ 。在大多数森林生态系统中, 细根生物量仅占地下总生物量的 $3 \%-30 \%{ }^{[2]}$, 但其周 转却消耗了生态系统净初级生产力的 $10 \%-75 \%{ }^{[3]}$ 。产生如此大的波动范围的主要原因是不同森林生态系

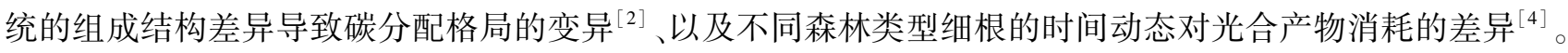
然而, 受研究方法和测定技术的限制, 森林生态系统细根时间动态及其影响因子仍然是森林生态学研究中了 解最少的一部分内容。

细根处于不断的产生、生长、衰老、死亡和再产生的周转过程中。其中, 细根的生长量 (FRP) 和死亡量 (FRM) 随季节的变化是细根时间动态的主要表现形式,受林木自身的生物因子 ${ }^{[1,5]}$ (如: 森林类型 ${ }^{[6]}$ 、胸高断 面积 ${ }^{[7]}$ 、林龄和郁闭度 ${ }^{[8]}$ 等) 和环境因子 (如: 土壤温度 $(T \mathrm{~s})$ 、土壤湿度 $(M \mathrm{~s})$ 等) 的共同影响 ${ }^{[3,9-10]}$ 。以往研

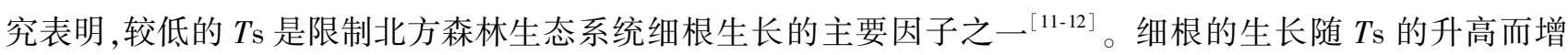
加, 达到最大值后则随 $T \mathrm{~s}$ 的持续升高而下降 ${ }^{[13]}$; 但 $T \mathrm{~s}$ 过高会加快细根死亡, 缩短细根寿命 ${ }^{[14]}$ 。当 $T \mathrm{~s}$ 在适合 范围内, 细根的生长和死亡会随土壤水分有效性的增加而增加 ${ }^{[15-16]}$ 。Quan 等 ${ }^{[6]}$ 测定了东北东部山区红松人 工林、硬阔叶林、杨华林、蒙古栋林、兴安落叶松人工林的 FRP 和 FRM 的季节动态, 因未能同步测定相关的生 物环境因子而将这 5 种温带森林的数据作混合分析, 发现总体上 FRP 和 FRM 与 $T \mathrm{~s}$ 之间存在显著的正相关关 系, 而与 $M \mathrm{~s}$ 之间存在显著的指数函数关系; 然而这些关系是否随林型而发生变化还不清楚。此外, 细根的生 长和维持需要消耗大量的碳水化合物 ${ }^{[1]}$, 而碳水化合物主要来源于叶片的光合作用。叶面积指数 (LAI) 能够 反映群体水平上叶子的生长和密度的变化, 并且和一定范围的光合作用密切相关, 进而影响着林分的光能利 用和产量 ${ }^{[17-18]}$ 。因此, 理论上细根的生长和死亡与 LAI 之间存在着一定的关系, 但这种关系是否存在以及是 否因林型而变化等问题还有待于验证。为此, 本文继续对东北东部山区 5 种温带森林生态系统的细根动态及 其相关因子进行连续跟踪测定, 旨在探索不同林型之间 FRP 和 FRM 的时间动态及其影响因子, 以便揭示温 带森林生态系统碳循环格局与过程的内在规律及其与环境变化之间的关系。

\section{1 材料和方法}

\section{1 研究地概况}

研究地点位于黑龙江帽儿山森林生态站 $\left(45^{\circ} 24^{\prime} \mathrm{N}, 127^{\circ} 40^{\prime} \mathrm{E}\right)$, 平均海拔 $400 \mathrm{~m}$, 平均坡度 $10^{\circ}-15^{\circ}$, 地 带性土壤为典型暗棕壤。该地区属大陆性温带季风气候, 四季较为分明,夏季短促而湿热, 冬季寒冷而干燥。 年均气温 $3.1{ }^{\circ} \mathrm{C}$, 年均降雨量 $629 \mathrm{~mm}$, 年均蒸发量 $864 \mathrm{~mm}$ 。现有植被是原地带性植被——阔叶红松林经干 扰后形成的人工林和天然次生林, 即红松 (Pinus koraiensis) 人工林、硬阔叶林 (以水曲柳 (Fraxinus mandshurica Rupr. ) 和胡桃楸 (Juglans mandshurica Maxim. ) 占优势)、杨华林 (以山杨 ( ( Populous davidiana) 和白桦 (Betula platyphylla) 占优势)、蒙古栋 ( Quercus mongolica) 林、兴安落叶松 (Larix gmelinii) 人工林等。林内主要灌木包 括: 丁香 (Syringa spp.)、卫矛 (Euonymus spp.)、绣线菊 (Spiraea spp.)、舅疏 (Deutzia spp.)、刺五加 (Radix 
acanthopanacis senticosl)、五味子 (Schizandra chinensis) 等; 主要草本植物包括: 苔草 (Carex spp.)、山茄子 (Brachybotrys paridiformis)、白花碎米荠(Cardamine leucantha)、木赋 (Equisetum spp. )、山芹( Ostericum spp. )、 菖麻 (Urtica spp.) 等。

\section{2 研究方法}

在林龄相近 (约 60 年) 的红松人工林、硬阔叶林、杨桦林、蒙古栎林和兴安落叶松人工林内各设置 3 块固 定样地 $(20 \mathrm{~m} \times 30 \mathrm{~m})$, 于 2006 年秋季在每块样地随机安装 5 根与地面呈 $45^{\circ}$ 角、垂直深度达 $40-45 \mathrm{~cm}$ 的聚 氯乙烯材料制成的透明圆形管 (微根管) (内径 $=5.5 \mathrm{~cm}$, 长度 $=90 \mathrm{~cm})^{[19-20]}$ 。用黑色胶布缠绕裸露在地表外 部约 $20 \mathrm{~cm}$ 长的微根管顶部以防止光线射人, 然后用黄色胶布覆盖以防止微根管内吸热, 并加盖密封顶端。 在微根管顶部外壁划刻方向线, 以保证每次取样时, 都能对同一位置的细根进行影像数据采集 ${ }^{[6]}$ 。

于 2010 年 5 月-10 月,采用微根管袖珍影像成像系统 (BTC- 2; Bartz Technology, Santa Barbara, CA， USA) 每隔 2-3 周 ${ }^{[21]}$ 对同一位置的细根进行动态影像收集 (图片实际大小为 $1.4 \mathrm{~cm} \times 1.8 \mathrm{~cm}$ ), 每根管每次 能取 40-45 个图片。采用 RootTrack 软件( Duke University Phytotron, Durham, NC, USA) 对所采集的影像进 行处理, 测定每个细根的直径、长度, 并根据细根颜色和形态区分为死根和活根 ${ }^{[14,22-23]}$, 计算得到单位时间、 单位根窗面积内的细根长度的生长量和死亡量, 分别作为细根生长量 $\left(\mathrm{FRP}, \mu \mathrm{m} \cdot \mathrm{cm}^{-2} \cdot \mathrm{d}^{-1}\right)$ 和死亡量 $(\mathrm{FRM}$, $\left.\mu \mathrm{m} \cdot \mathrm{cm}^{-2} \cdot \mathrm{d}^{-1}\right)$ 。

在每次微根管影像采集的同时, 测定土壤温度 $(T \mathrm{~s})$ 、土壤湿度 $(M \mathrm{~s})$ 和叶面积指数 ( $\mathrm{LAI})$ 。在每根微根管 周围 $15 \mathrm{~cm}$ 处任选三点、用便携式数字温度计(JM624) 和便携式土壤水分速测仪(TDR, CD620, USA) 自上而 下分别测定 $5 、 10 \mathrm{~cm}$ 和 $20 \mathrm{~cm}$ 的 $T \mathrm{~s}$ 和 $M \mathrm{~s}$, 最后取 3 个土层的平均 $T \mathrm{~s}$ 和 $M \mathrm{~s}$ 。采用冠层分析仪(WinSCANOPY 2006a, Canada) 测定 LAI。在每块样地内随机选取 5 个固定点, 每个固定点拍摄 3 张图像, 从中选择最好的一 张进行影像处理。为了消除人为误差, 在每个固定位置和高度 (离地面约 $1.5 \mathrm{~m}$ 处) 上做好标记, 以确保每次 都在同一地点拍摄图像; 为避免光照条件对测定结果产生影响,通常在多云天气或傍晚日落时段取像。LAI 影像采用 Digital Hemispherical Photography 软件(DHP; Canada Centre for Remote Sensing, Ottawa, Canada)分 析处理,并用 Photoshop 软件对木质部分进行校正,所得的 LAI 为有效叶面积。

\section{3 数据分析}

以样地为统计单位计算 5 种林型的 FRP 和 FRM, 将 $T \mathrm{~s} 、 M \mathrm{~s}$ 和 LAI 作为协变量, 采用协方差分析 (ANCOVA) 检验林型、采样时间及其交互作用对 FRP 和 FRM 的影响。采用一元线性、多元线性和非线性回 归法分析 FRP、FRM 与 $T \mathrm{~s} 、 M \mathrm{~s} 、$ LAI 之间的关系。所有数据均采用 SPSS17.0 (SPSS Inc., USA) 和 SigmaPlot 10.0 (Systat corporation, USA) 进行统计分析和绘图。

\section{2 结果}

2.1 土壤温度、土壤湿度、叶面积指数、细根生长量和死亡量的林型间差异

FRP 和 FRM 总体平均值和生长季内每次测定均值在林型间均存在显著性差异 $(P<0.001$; 表 1 和图 1)。

表 15 种林型细根生长量 (FRP)、细根死亡量 $(\mathrm{FRM})$ 、土壤温度 $(T \mathrm{~s})$ 、土壤湿度 $(M \mathrm{~s})$ 和叶面积指数 ( LAI $)$ 平均值 (标准误)

Table 1 Means ( standard errors) of fine root production (FRP), fine root mortality (FRM), soil temperature $\left(T_{\mathrm{s}}\right)$, soil moisture $(M \mathrm{~s})$, and leaf area index (LAI) for the five forest types

\begin{tabular}{|c|c|c|c|c|c|}
\hline $\begin{array}{l}\text { 林型 } \\
\text { Forest types }\end{array}$ & $\begin{array}{c}\text { 细根生长量 } \\
\text { FRP } \\
/\left(\mu \mathrm{m} \cdot \mathrm{cm}^{-2} \cdot \mathrm{d}^{-1}\right)\end{array}$ & $\begin{array}{c}\text { 细根死亡量 } \\
\text { FRM } \\
/\left(\mu \mathrm{m} \cdot \mathrm{cm}^{-2} \cdot \mathrm{d}^{-1}\right)\end{array}$ & $\begin{array}{c}\text { 土壤温度 } \\
T_{\mathrm{s}} \\
{ }^{\circ} \mathrm{C}\end{array}$ & $\begin{array}{c}\text { 土壤湿度 } \\
M \mathrm{~s} \\
1 \%\end{array}$ & $\begin{array}{c}\text { 叶面积 } \\
\text { LAI } \\
/\left(\mathrm{m}^{2} / \mathrm{m}^{2}\right)\end{array}$ \\
\hline 杨桦林 $P$. davididiana-B. platyphylla forest & $13.34(0.90) \mathrm{A}$ & $5.02(0.36) \mathrm{B}$ & $12.59(0.09) \mathrm{B}$ & $32.36(2.45) \mathrm{B}$ & $1.16(0.04) \mathrm{B}$ \\
\hline 硬阔叶林 Hardwood forest & $13.04(0.82) \mathrm{A}$ & $6.85(0.32) \mathrm{A}$ & $12.52(2.25) \mathrm{B}$ & $41.71(6.23) \mathrm{A}$ & $1.10(0.25) \mathrm{B}$ \\
\hline 兴安落叶松人工林 L. gmelinii plantation & $8.74(1.14) \mathrm{B}$ & $5.05(0.61) \mathrm{B}$ & $11.30(0.19) \mathrm{D}$ & $28.53(0.54) \mathrm{B}$ & $1.25(0.08) \mathrm{B}$ \\
\hline 红松人工林 $P$. koraiensis plantation & $8.02(2.27) \mathrm{B}$ & $3.88(0.35) \mathrm{B}$ & $11.91(0.11) \mathrm{C}$ & $32.20(1.18) \mathrm{B}$ & $1.79(0.02) \mathrm{A}$ \\
\hline 蒙古栎林 $Q$. mongolica forest & $7.59(0.82) \mathrm{B}$ & $3.88(0.61) \mathrm{B}$ & $14.18(0.14) \mathrm{A}$ & $25.21(1.36) \mathrm{B}$ & $1.10(0.13) \mathrm{B}$ \\
\hline
\end{tabular}

表中的 $A 、 B 、 C 、 D$ 表示 HSD 检验显著性差异组别 $(\alpha=0.05)$ 
5 林型 FRP 总体平均值波动在 7.59-13.34 $\mu \mathrm{m} \cdot \mathrm{cm}^{-2}$. $\mathrm{d}^{-1}$ 之间, 其顺序为: 杨桦林 > 硬阔叶林 > 兴安落叶松 林 $>$ 红松林 > 蒙古栎林; FRM 总体平均值波动在 3. $88-6.85 \mu \mathrm{m} \cdot \mathrm{cm}^{-2} \cdot \mathrm{d}^{-1}$ 之间, 其顺序为: 硬阔叶林 > 兴安落叶松林 $>$ 杨桦林 $>$ 蒙古柇林 $>$ 红松林 $($ 表 1$)$ 。 在生长季前期硬阔叶林和杨桦林具有最高的 FRP 和 FRM,落叶松林和蒙古栋林则分别具有最低的 FRP 和 FRM; 而在生长季后期落叶松林 FRP 和 FRM 显著高于 其它林型, 蒙古栋林则拥有最小 FRP 和 FRM。林型间 的 $T \mathrm{~s}$ 和 LAI 存在显著性差异 $(P<0.05)$, 其平均值分 别波动在 $11.30-14.18{ }^{\circ} \mathrm{C}$ 和 $1.10-1.79 \mathrm{~m}^{2} / \mathrm{m}^{2}$ 之间 (表 1 ), 而硬阔叶林的 $M \mathrm{~s}(41.71 \%$ ) 显著地高于其它林 型 (平均值为 $32.00 \%$ )。以 $T \mathrm{~s} 、 M \mathrm{~s}$ 和 LAI 为协变量的 协方差分析发现,林型及其与采样时间的交互作用显著 地影响 FRP 和 $\operatorname{FRM}(P<0.001$, 表 2$)$ 。

2.2 土壤温度、土壤湿度、叶面积指数、细根生长量和 死亡量的季节变化

5 种林型的 $T \mathrm{~s}$ 虽然有差异, 但总体上均随生长季 的进程而呈现单峰曲线变化 (图 1), 在 209d 达到最大 值 (变化范围为 $16.34-18.74{ }^{\circ} \mathrm{C}$ )。 $M \mathrm{~s}$ 的林型间差异 较大, 波动在 $14.38 \%-67.39 \%$ 之间; 但所有林型的 $M \mathrm{~s}$ 季节变化趋势相近,均表现为近似于 “ $\mathrm{W}$ ” 型: 生长季初 期因融雪水补充而达到最高、5 月下旬至 6 月出现最低 值、7-8 月维持在较高水平但波动较大、9 月再出现低 谷、之后因降雪融水而回升的趋势 (图 1)。

5 种林型 LAI 呈现明显的抛物线模式的季节动态 (图 1)。在 $122 \mathrm{~d}$ 时,树木还处于发芽阶段, LAI 趋近于 零 (除红松林外); 到 139d 时, 除红松林外其他 4 个林 型已经开始展叶; 之后不同林型 LAI 峰值出现时间依次 是: 蒙古栋林 $162 \mathrm{~d}$, 杨桦林 $182 \mathrm{~d}$, 兴安落叶松林、红松林 和硬阔叶林 $209 \mathrm{~d}$; 生长季末期 LAI 再度回到低值 (图 1)。

生长季节显著地影响 FRP 和 FRM (表 2), 不同的 林型之间 FRP 和 FRM 的季节变化规律差异明显 (图 1)。5 种林型的 FRP 在生长季中均表现为单峰型, 但 其峰值出现的时间不一(图 1d)。杨桦林和兴安落叶松 林 FRP 最小值均出现在 $122 \mathrm{~d}$, 而硬阔叶林、红松林和蒙 古楿林则出现在 $291 \mathrm{~d}$ (变化范围为 $0-1.83 \mu \mathrm{m} \cdot \mathrm{cm}^{-2}$. $\left.\mathrm{d}^{-1}\right) 。 F R P$ 最大值出现的时间依次为: 硬阔叶林 $182 \mathrm{~d}$ 、 红松林和蒙古栋林 $209 \mathrm{~d}$ 、杨桦林 $228 \mathrm{~d}$ 、兴安落叶松林 $250 \mathrm{~d}$; 最大值的顺序为: 杨桦林 $\left(31.85 \mu \mathrm{m} \cdot \mathrm{cm}^{-2} \cdot \mathrm{d}^{-1}\right)>$

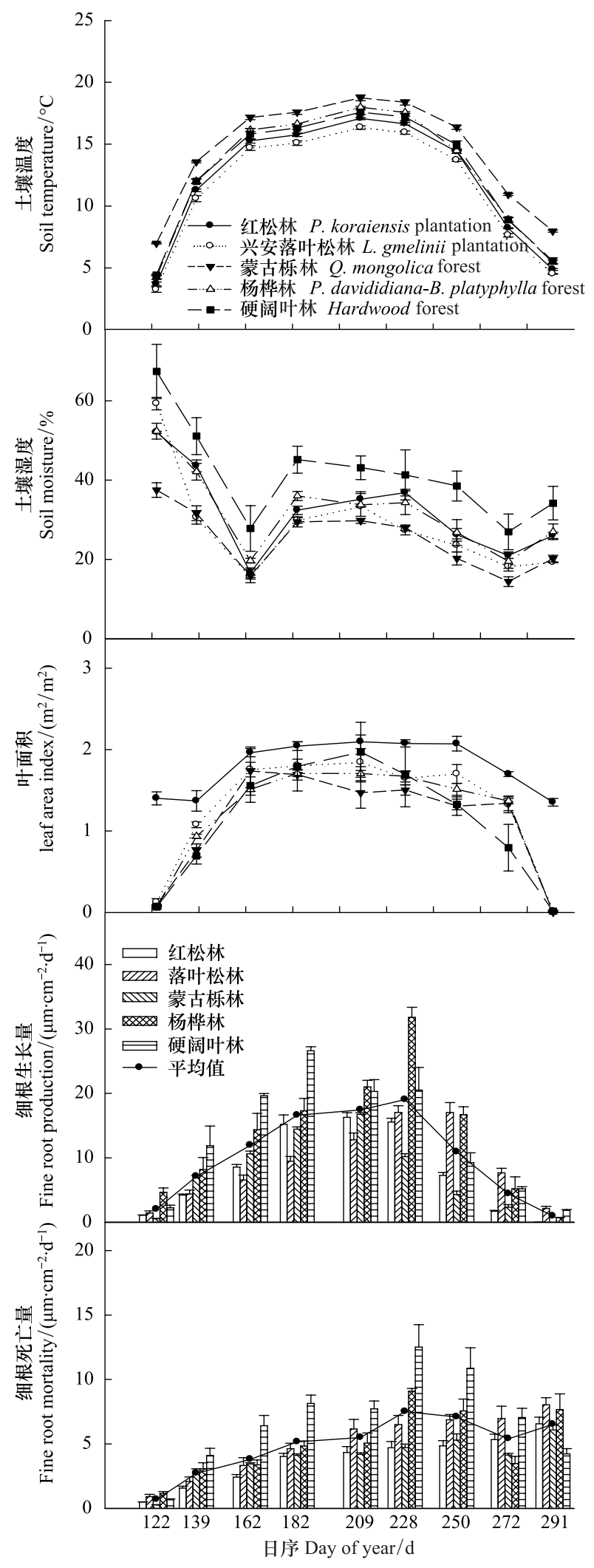

图 15 种林型土壤温度、土壤湿度、叶面积指数、细根生长量和死 亡量的季节动态

Fig. 1 Seasonal dynamics of soil temperature $(T \mathrm{~s})$, soil moisture $(M \mathrm{~s})$, leaf area index $(\mathrm{LAI})$, fine root production $(\mathrm{FRP})$, and fine root mortality ( FRM) for the five forest types 
硬阔叶林 $\left(26.60 \mu \mathrm{m} \cdot \mathrm{cm}^{-2} \cdot \mathrm{d}^{-1}\right)>$ 蒙古栋林 $\left(17.28 \mu \mathrm{m} \cdot \mathrm{cm}^{-2} \cdot \mathrm{d}^{-1}\right)>$ 兴安落叶松林 $\left(17.04 \mu \mathrm{m} \cdot \mathrm{cm}^{-2} \cdot \mathrm{d}^{-1}\right)>$ 红松 林 $\left(16.86 \mu \mathrm{m} \cdot \mathrm{cm}^{-2} \cdot \mathrm{d}^{-1}\right)$ 。

5 种林型 FRM 最小值均出现在 $122 \mathrm{~d}$ (图 1 ), 变化范围为 $0.26-1.16 \mu \mathrm{m} \cdot \mathrm{cm}^{-2} \cdot \mathrm{d}^{-1}$ 。随生长季进程, FRM 逐渐增加, 硬阔叶林和杨华林 FRM 在 $228 \mathrm{~d}$ 出现峰值, 随后下降; 而其它 3 种林型的 FRM 峰值均出现在生长 季末期的 $291 \mathrm{~d}$, 变化范围为 $6.07 \mu \mathrm{m} \cdot \mathrm{cm}^{-2} \cdot \mathrm{d}^{-1}$ (蒙古栋林) $-12.51 \mu \mathrm{m} \cdot \mathrm{cm}^{-2} \cdot \mathrm{d}^{-1}$ (硬阔叶林)。

表 2 林型和采样时间对细根生长量 (FRP)、细根死亡量 (FRM) 影响的协方差分析表

Table 2 The ANCOVA table of effects of forest types and sampling times on fine root production and mortality

\begin{tabular}{llrrrrr}
\hline 细根变量 & 变异来源 & $\begin{array}{c}\text { 自由度 } \\
\text { Root variable }\end{array}$ & $\begin{array}{c}\text { 方差 } \\
\text { Source of variance }\end{array}$ & $\begin{array}{c}\text { 均方差 } \\
\text { MS }\end{array}$ & $F$ & $P$ \\
\hline 细根生长量 & 林型 Forest types & $4 / 87$ & 370.59 & 92.65 & 14.71 & $<0.001$ \\
FRP $/\left(\mu \mathrm{m} \cdot \mathrm{cm}^{-2} \cdot \mathrm{d}^{-1}\right)$ & 采样时间 Sampling times & $8 / 87$ & 384.77 & 48.10 & 7.64 & $<0.001$ \\
& 林型 ×采样时间 Forest types $\times$ Sampling times & $32 / 87$ & 1406.74 & 43.96 & 6.98 & $<0.001$ \\
细根死亡量 & 林型 Forest types & $4 / 87$ & 42.64 & 10.66 & 7.09 & $<0.001$ \\
FRM $/\left(\mu \mathrm{m} \cdot \mathrm{cm}^{-2} \cdot \mathrm{d}^{-1}\right)$ & 采样时间 Sampling times & $8 / 87$ & 310.04 & 38.75 & 25.77 & $<0.001$ \\
& 林型 $\times$ 采样时间 Forest types $\times$ Sampling times & $32 / 87$ & 194.35 & 6.07 & 4.04 & $<0.001$ \\
\hline
\end{tabular}

以土壤温度、土壤湿度和叶面积指数作为协变量

\section{3 细根生长量和死亡量与土壤温度、土壤湿度和叶面积指数的关系}

除了硬阔叶林 FRM 与 $M \mathrm{~s}$ 的关系不显著外 $(P=0.08)$, 所有林型的 FRP 和 FRM 与 $T \mathrm{~s} 、 M \mathrm{~s}$ 和 LAI 的关系 均显著 $(P<0.05)$, 决定系数 $\left(R^{2}\right)$ 波动在 $0.15-0.88$ 之间,但回归模型因林型和自变量而异 (图 2$)$ 。除蒙古 栋林的 FRP 与 $T \mathrm{~s}$ 和 LAI 均呈显著正相关外,所有林型的 FRP 和 FRM 则均与 $T \mathrm{~s}$ 和 LAI 呈显著的指数函数关 系 (图 2)。除硬阔叶林外, 所有林型的 FRP 和 FRM 与 $M \mathrm{~s}$ 均呈显著的二次函数关系, 但不同林型 FRP 和 FRM 的最适 $M \mathrm{~s}$ 范围不同,其中 FRP 的最适 $M \mathrm{~s}$ 以蒙古栋林最低 (26.69\%)、硬阔叶林最高 (43.40\%), FRM 则以兴安落叶松林最低 $(19.08 \%)$ 、硬阔叶林最高 $(36.74 \%)$ 。

多元回归分析表明, $T \mathrm{~s}$ 和 $M \mathrm{~s}$ 解释了 FRP 变异性的 60\%-81\%、FRM 变异性的 $29 \%-73 \%$; 增加 LAI 为 自变量之后, $R^{2}$ 分别提高至 $0.68-0.86$ 和 $0.53-0.88, R^{2}$ 的提高程度因林型而异(表 3 )。总体而言,这 3 个 自变量对 FRP 变异性的解释率高于对 FRM 的解释率。

\section{3 讨论}

3.1 细根生长量和死亡量的季节动态及其影响因子

温带森林由于受到气候和生物因子的共同控制, 其地上和地下生长过程具有明显的季节动态 ${ }^{[24-25]}$ 。本 研究结果显示, $T \mathrm{~s} 、 M \mathrm{~s}$ 和 LAI 的联合作用影响着 5 种温带森林生态系统细根生长与死亡的季节动态 ( 图 1 , 表 3 )。大多数温带森林春季细根生长分为两种形式:一是细根先于叶生长 (多为落叶阔叶树种), 这需要利用上 一年树体中储存的碳水化合物; 二是细根与叶同步生长 (多为常绿针叶树种), 以利用叶片新固定的光合产物 为主 ${ }^{[24,26]}$ 。生长季初期气温较低, 树木刚刚展叶, 虽然大量融雪水增加了 $M \mathrm{~s}$, 但 FRP 仍然很低 (图 1 ), 这时 较低的 $T \mathrm{~s}$ 是细根生长的主要限制因子 ${ }^{[11-12]}$, 而细根的死亡可能与存储的光合产物消耗有关 ${ }^{[26-27]}$ 。在生长季 中期随着温度和降水的增加, 叶面积逐渐增大, 树木光合能力增强, 为了获取足够的土壤水分和养分, 细根开 始大量生长 ${ }^{[28]}$ 。本研究中除硬阔叶林外, 其它林型的 FRP 和 FRM 最大值均出现在 $M \mathrm{~s}$ 和 $T \mathrm{~s}$ 达到最大值 (209d) 且 LAI 为最高值 (162-209d) 后或是同步,适合的土壤温湿度和充足的光合底物共同影响着细根的生 长和死亡。随着秋季气温的逐渐降低, 叶片的逐渐衰老和不断调落, 地上部分对养分、水分的需求持续降 低 ${ }^{[29]}$, 导致 FRP 开始下降并在生长季末期达到最低值, 而 FRM 则逐步达到峰值(图 1)。总体而言, 在生长季 初期和末期土壤温度和光合底物的供应是控制细根生长和死亡的主要因子, 且呈正相关关系, 而在生长中期 则受到 $T \mathrm{~s} 、 M \mathrm{~s}$ 和 $\mathrm{LAI}$ 的联合调控(图 1 和图 2)。 

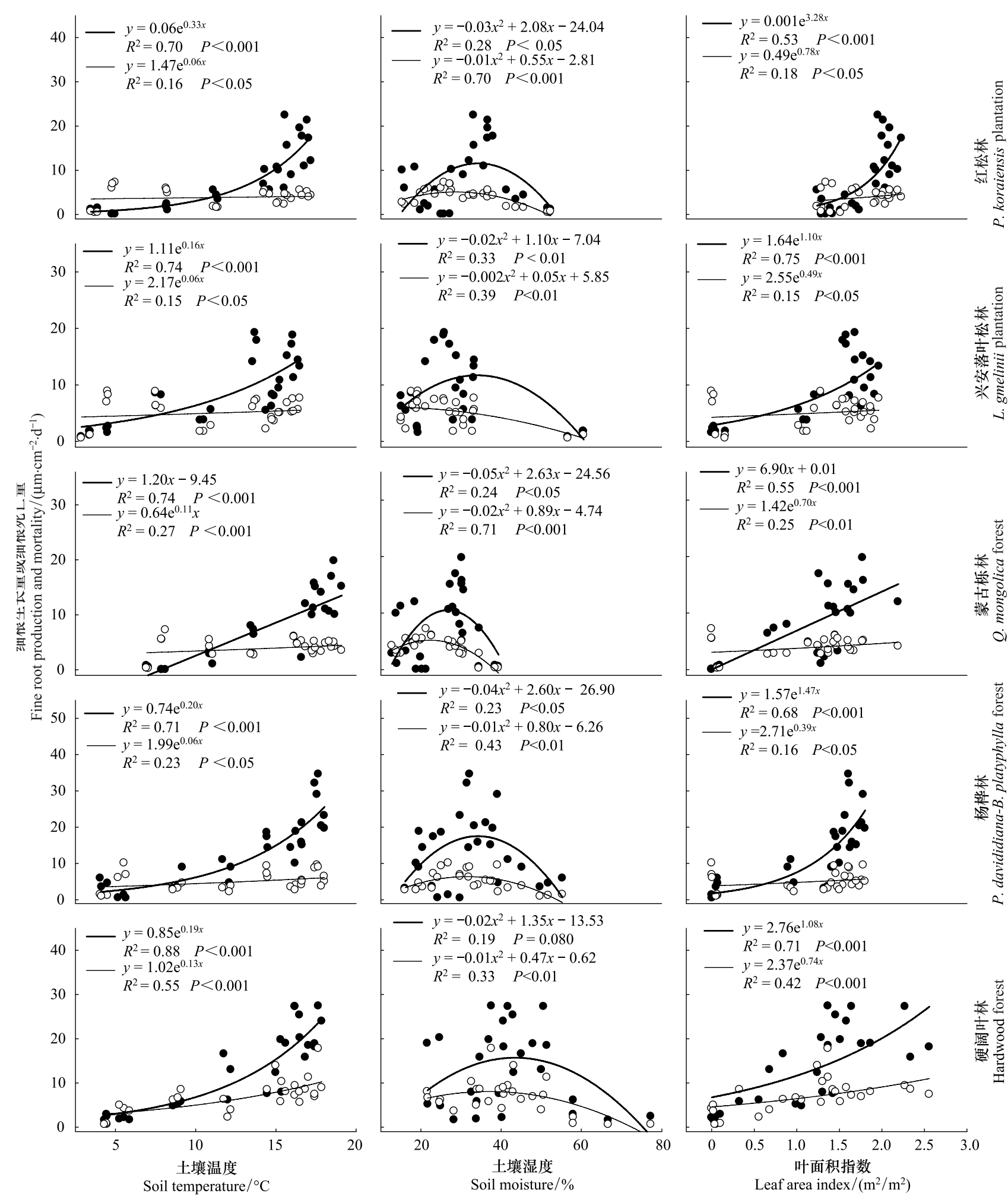

图 25 种林型细根生长量、死亡量随土壤温度、土壤湿度和叶面积指数变化

Fig. 2 Fine root production and mortality versus soil temperature, soil moisture and leaf index area

本研究中虽然 FRP 和 FRM 具有相似的驱动因子, 但是由于各自对驱动因子的响应机理不同, 导致两者 间存在明显的季节动态差异 (图 1 和图 2)。FRP 季节动态与 $T \mathrm{~s}$ 和 LAI 变化趋势相似,且 $T \mathrm{~s} 、$ LAI 对 FRP 影响 程度较高, 而 $M \mathrm{~s}$ 较低( 图 2)。 $T \mathrm{~s} 、 M \mathrm{~s}$ 和 LAI 综合作用可以解释 FRP 变异性的 $68 \%-86 \%$,而 LAI 的生长又 
主要受大气温度影响, 显示了细根生长过程中对温度的高度依赖性。本研究中 5 种林型细根生长的起始温度 变化范围为 $3.24-6.98^{\circ} \mathrm{C}$, 与 Burke 等 ${ }^{\left[{ }^{[0]}\right.}$ 和 Webb 等 ${ }^{[31]}$ 研究结果一致。相对于 FRP, FRM 与 $T \mathrm{~s}$ 、 LAI 回归关 系弱些,但与 $M \mathrm{~s}$ 关系较强,Tierney 等 ${ }^{[33]}$ 研究也发现 FRM 与 $T \mathrm{~s}$ 存在弱正相关。因此,研究结果表明 FRP 和 FRM 对温度的敏感程度不同,这与以往研究结果相似 ${ }^{[32]}$ 。细根的死亡是个复杂的生理生态过程, 除了环境 变量外,树木的内在因素 (如碳水化合物的供给)也强烈影响着细根的死亡 ${ }^{[1]}$ 。此外,在高温多雨的夏季,地 上和地下养分竞争强烈, 会造成局部尺度养分耗竭,加快细根的死亡 ${ }^{[14]}$,细根的死亡也可能与环境资源的空 间异质性有关。

表 3 细根生长量 $(\mathrm{FRP})$ 和死亡量 $(\mathrm{FRM})$ 与土壤温度 $(T \mathrm{~s})$ 、土壤湿度 $(M \mathrm{~s})$ 和叶面积指数 $(\mathrm{LAI})$ 的多元回归分析*

Table 3 Multiple regression of fine root production (FRP) or mortality (FRM) against soil temperature $(T \mathrm{~s})$, soil moisture $(M \mathrm{~s})$, and leaf area index (LAI) for the five forest types

\begin{tabular}{|c|c|c|c|c|c|c|c|}
\hline \multirow{2}{*}{$\begin{array}{l}\text { 应变量 } \\
\text { Dependent } \\
\text { variable }\end{array}$} & \multirow{2}{*}{$\begin{array}{l}\text { 林型 } \\
\text { Forest types }\end{array}$} & \multicolumn{3}{|c|}{$\begin{array}{c}\text { 自变量 Independent variable } \\
T T_{\mathrm{s}}+M \mathrm{~s}\end{array}$} & \multicolumn{3}{|c|}{$\begin{array}{c}\text { 自变量 Independent variable } \\
T \mathrm{~s}+M \mathrm{~s}+\text { LAI }\end{array}$} \\
\hline & & $\begin{array}{c}\text { 决定系数 } \\
R^{2}\end{array}$ & $\begin{array}{c}\text { 变异系数 } \\
C V\end{array}$ & $\begin{array}{c}\text { 均方差 } \\
\text { MSE }\end{array}$ & $\begin{array}{c}\text { 决定系数 } \\
R^{2}\end{array}$ & $\begin{array}{c}\text { 变异系数 } \\
C V\end{array}$ & $\begin{array}{c}\text { 均方差 } \\
\text { MSE }\end{array}$ \\
\hline 细根生长量 & 红松林 $P$. koraiensis plantation & 0.75 & 47.20 & 3.78 & 0.85 & 39.49 & 3.17 \\
\hline \multirow[t]{4}{*}{ FRP } & 兴安落叶松林 L. gmelinii plantation & 0.60 & 44.79 & 3.91 & 0.68 & 44.17 & 3.86 \\
\hline & 蒙古栎林 $Q$. mongolica forest & 0.81 & 37.07 & 2.81 & 0.86 & 35.35 & 2.68 \\
\hline & 杨桦林 $P$. davididiana-B. platyphylla forest & 0.74 & 38.82 & 5.18 & 0.79 & 38.26 & 5.10 \\
\hline & 硬阔叶林 Hardwood forest & 0.76 & 36.22 & 4.72 & 0.78 & 38.17 & 4.98 \\
\hline 细根死亡量 & 红松林 P. koraiensis plantation & 0.73 & 27.65 & 1.07 & 0.88 & 20.43 & 0.79 \\
\hline \multirow[t]{4}{*}{ FRM } & 兴安落叶松林 L. gmelinii plantation & 0.53 & 36.35 & 1.84 & 0.73 & 29.98 & 1.51 \\
\hline & 蒙古栋林 $Q$. mongolica forest & 0.60 & 29.77 & 1.16 & 0.74 & 26.51 & 1.03 \\
\hline & 杨桦林 $P$. davididiana-B. platyphylla forest & 0.29 & 47.31 & 2.38 & 0.53 & 42.66 & 2.14 \\
\hline & 硬阔叶林 Hardwood forest & 0.55 & 40.39 & 2.77 & 0.60 & 41.92 & 2.87 \\
\hline
\end{tabular}

所有的回归分析均为显著 $(N=27, P<0.05)$

3.2 细根生长量和死亡量季节动态的林型间差异

5 种林型间 FRP 和 FRM 季节动态均存在明显差异 (表 1 和图 1 ), 这是林型自身以及环境因子综合作用 的结果 ${ }^{[1]}$ 。在生长季节内的每次测定均存在显著的林型差异, 而这种林型差异随着生长季的进程而呈现出 不同的趋势,这说明林型是导致细根生长死亡的差异的重要因素, 且在细根生长和死亡的不同时期具有不同 的影响程度。硬阔叶林 FRP 峰值出现时间在 $T \mathrm{~s}$ 和 LAI 之前, 这是由于林内较多的树种生长物候不同步造成 的, 尤其是林下灌木细根生长启动要早于乔木; 而其余 4 林型的植被组成较简单, FRP 峰值出现时间则与 $T \mathrm{~s}$ 和 LAI 同步或稍晚; 同理, 硬阔叶林的 FRM 峰值出现的时间也稍早于其余几种林型。此外, 在相同气候条件 下, 不同林型间 $T \mathrm{~s}$ 和 $M \mathrm{~s}$ 存在显著差异 (表 2), 且 FRP 和 FRM 均与 $T \mathrm{~s}$ 和 $M \mathrm{~s}$ 显著相关(图 2)。研究结果表明 不同林型细根生长和死亡对水热条件的敏感程度不同, $T \mathrm{~s}$ 和 $M \mathrm{~s}$ 共同解释了 FRP 变异性的 $60 \%-81 \%$ 和 FRM 变异性的 29\%-73\%,这会导致 FRP 和 FRM 的季节变化动态的林型间差异。本研究中, 硬阔叶林 FRP 与 $M \mathrm{~s}$ 弱相关, 这是因为该林型地处地势平缓和沟谷地带, 易积水, 湿度不是细根生长的限制因子。相反, 蒙 古柇林和杨华林样地位于山坡中上部, 土壤较干旱, 水分限制了其细根的生长。Pregitzer 等 ${ }^{[24]}$ 认为不同立地 条件下以及生长季内的水热条件差异强烈地影响着细根的生长和死亡, 相似的结果在其他的研究中也有所体 现 ${ }^{[2,29]}$ 。以往研究发现, 温带森林的细根生长主要是由叶片所固定的光合产物来供给 ${ }^{[24]}$, 与叶片生长和密度 变化密切相关, 本研究也发现 FRP、FRM 均与 LAI 显著正相关(图 2), 且林型间 LAI 存在显著差异, 因此, LAI 的变异也是导致 FRP 和 FRM 林间差异的因素之一,且联合土壤温湿度后可以共同解释 FRP 和 FRM 变异性 的 $68 \%-86 \%$ 和 $53 \%-88 \%$ 。

\section{4 结论}

东北东部山区 5 种典型森林生态系统的 FRP 和 FRM 具有明显的季节动态和林型差异, 这种差异主要是 
由林内 $T \mathrm{~s} 、 M \mathrm{~s}$ 和 LAI 的作用引起的,3 个因子的综合作用对 FRP 和 FRM 变异性的解释率分别达 $68 \%$ 和 $53 \%$ 以上,表明温带森林生态系统细根生长和死亡的时间动态主要受土壤温湿度和叶面积变化的联合影响。

致谢: 感谢黑龙江帽儿山森林生态系统国家野外科学观测研究站提供的野外基础支持。

\section{References:}

[ 1 ] Eissenstat D M, Yanai R D. The ecology of root lifespan. Advances in Ecological Research, 1997, 27: 1-60.

[ 2 ] Vogt K A, Vogt D J, Vogt P A, Palmiotto P A, Boon P, O'Hara J, Asbjomsen H. Review of root dynamics in forest ecosystems grouped by climate, climatic forest type and species. Plant and Soil, 1996, 187(2): 159-219.

[ 3 ] Bloomfield J, Vogt K A, Wargo P M. Tree root turnover and senescence// Yoav Waisel, Amram Eshel, U. Kafkafi, eds. Plant Roots: the hidden half. New York: Marcel Dekker, 1996: 363-382.

[ 4 ] Gill R A, Jackson R B. Global patterns of root turnover for terrestrial ecosystems. New Phytologist, 2000, 147 (1) : 13-31.

[ 5 ] Espeleta J F, West J B, Donovan L A. Tree species fine-root demography parallels habitat specialization across a sandhill soil resource gradient. Ecology , 2009, 90(7): 1773-1787.

[ 6 ] Quan X K, Wang C K, Zhang Q Z, Wang X C, Luo Y Q, Bond-Lanberty B. Dynamics of fine roots in five Chinese temperate forests. Journal of Plant Research, 2010, 123(4): 497-507.

[ 7 ] Finer L, Ohashi M, Noguchi K, Hirano Y. Factors causing variation in fine root biomass in forest ecosystems. Forest Ecology and Management, $2011,261(2): 265-277$.

[ 8 ] Vogt K A, Grier C C, Vogt D J. Production, turnover, and nutrient dynamics of above-and belowground detritus of world forests. Advances in Ecological Research, 1986: 303-366.

[ 9 ] Huang J H, Han X G, Chen L Z. Advances in the research of ( fine) root biomass in forest ecosystems. Chinese Acta Ecologica Sinica, 1999, 19 (2) : 270-277.

[10] Zhang X Q, Wu K H. Fine root production and turnover for forest ecosystems. Chinese Scientia Silvae Sinicae, 2001, 37(3): 126-138.

[11] Gower S T, Krankina O, Olson R J, Apps M, Linder S, Wang C. Net primary production and carbon allocation patterns of boreal forest ecosystems. Ecological Applications, 2001, 11(5):1395-1411.

[12] Ruess R W, Hendrick R L, Burton A J, Pregitzer K S, Sveinbjomsson B, Allen M E, Maurer G E. Coupling fine root dynamics with ecosystem carbon cycling in black spruce forests of interior Alaska. Ecological Monographs, 2003, 73(4) : 643-662.

[13] McMichale B L, Burke J J. Temperature effects on root growth// Yoav Waisel, Amram Eshel, U. Kafkafi eds. Plant Roots: the hidden half. New York: Marcel Dekker, 2002: 717-728.

[14] Burton A J, Pregitzer K S, Hendrick R L. Relationships between fine root dynamics and nitrogen availability in Michigan northern hardwood forests. Oecologia, 2000, 125(3): 389-399.

[15] Kuhns M R, Garre H E, Teskey R O, Hinckley T M. Root growth of black walnut trees related to soil temperature, soil water potential, and leaf water potential. Forest Science, 1985, 31(3): 612-629.

[16] Teskey R O, Hinckley T M. Influence of temperature and water potential on root growth of white oak. Physiologia Plantarum, 1981, 52(3): 363-369.

[17] Wang X Q, Ma L Y, Jia Z K, Xu C Y. Research and application advances in leaf area index. Chinese Journal of Ecology, 2005, 24 (5): 537-541.

[18] Zhang J H, Han S J, Yu G R. Seasonal variation in carbon dioxide exchange over a 200-year-old Chinese broad-leaved Korean pine mixed forest. Agricultural and Forest Meteorology, 2006, 137(3): 150-165.

[19] Smit A L, Bengough A G, Engels C. Root methods a handbook. Berlin: Spinger Verlag, 2000 : 211-235.

[20] Johnson M G, Tingey D T, Phillips D L, Storm M J. Advancing fine root research with minirhizotrons. Environmental and Experimental Botany, $2001,45(3): 263-289$.

[21 ] Joslin J D, Wolf M H, Impacts of water input manipulations on fine root production and mortality in a mature hard wood forest. Plant and Soil, 1998, 204(2): 165-174.

[22] Pregitzer K S, Hendrick R L, Fogel R. The demography of fine roots in response to patches of water and nitrogen. New Phytologist, 1993, 125 (3) : 575-580

[23] Wells C E, Eissenstant D M. Beyond the roots of young seedlings: the influence of age and order on fine root physiology. Journal of Plant Growth Regulation, 2003, 21 (4) : 324-334.

[24] Pregitzer K S, King J S, Burton A J, Brown S E. Responses of tree fine roots to temperature. New Phytologist, 2000 , 147(1) : $105-115$.

http://www. ecologica. cn 
[25] Fahey T J, Hughes J W. Fine-root dynamics in a northern hardwood forest ecosystem, Hubbard Brook experimental forest, NH. Journal of Ecology 1994, 82(3): 533-548.

[26] Pregitzer K S. Woody plants, carbon allocation and fine roots. New Phytologist, 2003, 158(3):421-423.

[27] Anderson L J, Comas L H, Lakso A N, Eissenstat D M. Multiple risk factors in root survivorship: a 4-year study in Concord grape. New Phytologist, 2003, 158(3): 489-501.

[28 ] Hendrick R L, Pregitzer K S. The dynamics of fine root length, biomass, and nitrogen content in two northern hardwood ecosystems. Canadian Journal of Forest Research, 1993, 23(12): 2507-2520.

[29] Brassard B W, Chen H Y H, Bergeron Y. Influence of environmental variability on root dynamics in northern forests. Critical Reviews in Plant Sciences, 2009, 28(3): 179- 197.

[30 ] Burke M K, and Raynal D J. Fine root growth phenology, production, and turnover in a northern hardwood forest ecosystem. Plant and Soil, 1994, 162(1) : 135-146.

[31] Webb D P. Root growth in Acer saccharum marsh, seedlings; effects of light intensity and photoperiod on root elongation rates. Botanical Gazette, 1976, 137 (3) : 211-217.

[32] Huang J X, Ling H, Yang Z J, Lu Z L, Xiong D C, Chen G S, Yang Y S, Xie J S. Estimating fine root production and mortality in subrrpical Altingia grilipes and Castanopsis carlesii forest. Acta Ecologica Sinica, 2012, 32(14) : 4472-4480.

[33 ] Tierney G L, Fahey T J, Groffman P M, Hardy J P, Fitzhugh R D, Driscoll C T, Yavitt J B. Environmental control of fine root dynamics in a northern hardwood forest. Global Change Biology, 2003, 9(5): 670-679.

\section{参考文献:}

[ 9 ] 黄建辉,韩兴国,陈灵芝. 森林生态系统根系生物量研究进展. 生态学报,1999,19(2):270-277.

[10］张小全, 吴可红. 森林细根生产和周转研究. 林业科学,2001,37(3):126-138.

[17] 王希群,马履一,贾忠奎,徐程扬. 叶面积指数的研究和应用进展. 生态学杂志, 2005,24(5):537-541.

[32] 黄锦学, 凌华, 杨智杰, 卢正立, 熊德成, 陈光水, 杨玉盛, 谢锦升. 中亚热带细柄阿丁枫和米槠群落细根的生产和死亡动态. 生态学报, 2012,32 (14) :4472-4480. 


\section{ACTA ECOLOGICA SINICA Vol. 33, No.13 Jul. ,2013 (Semimonthly) CONTENTS}

\section{Frontiers and Comprehensive Review}

A review of ecological effects of remnant trees in degraded forest ecosystems after severe disturbances

MIAO Ning, LIU Shirong, SHI Zuomin, et al (3889)

Mechanism and application of bioremediation to heavy metal polluted soil using arbuscular mycorrhizal fungi

LUO Qiaoyu, WANG Xiaojuan, LIN Shuangshuang, et al (3898)

\section{Autecology \& Fundamentals}

Changes of allometric relationships among leaf traits in different ontogenetic stages of Acer mono from different types of

forests in Donglingshan of Beijing

YAO Jing, LI Ying, WEI Liping, et al (3907)

The combined effects of increasing $\mathrm{CO}_{2}$ concentrations and different temperatures on the growth and chlorophyll fluorescence in

Porphyra haitanensis (Bangiales, Rhodophyta)

LIU Lu, DING Liuli, CHEN Weizhou, et al (3916)

Research on biomass expansion factor of chinese fir forest in Zhejiang Province based on LULUCF greenhouse gas Inventory

ZHU Tangjun,SHEN Chuchu,JI Biyong, et al (3925)

Influence of soil gradual drought stress on Acorus calamus growth and photosynthetic fluorescence characteristics

WANG Wenlin, WAN Yinjing, LIU Bo, et al (3933)

Isolation, identification, real-time PCR investigation of an endophytic phosphate-solubilizing bacteria from Caragana korshinskii

Kom. roots

ZHANG Lizhen, FENG Lili, MENG Qiuxia, et al (3941)

Plant's and soil organism's diversity across a range of Eucalyptus grandis plantation ages

ZHANG Danju, ZHANG Jian, YANG Wanqin, et al (3947)

Effects of diet and starvation on growth and survival of Scapharca broughtonii larvae

WANG Qingzhi, ZHANG Ming, FU Chengdong, et al (3963)

Multidrug-resistant bacteria in livestock feces

QI Shiyue, REN Siwei, LI Xueling, et al (3970)

Physiological regulation related to the decline of Alexandrium catenella

MA Jinhua, MENG Xi, ZHANG Shu, et al (3978)

Numerical simulation of water quality based on environmental fluid dynamics code for grass-algae lake in Inner Mongolia

LI Xing, SHI Hongsen,ZHANG Shuli, et al (3987)

Population, Community and Ecosystem

Influence of enclosure on Glyeyrrhiza uralensis community and distribution pattern in arid and semi-arid areas

LI Xuebin, CHEN Lin, LI Guoqi, et al (3995)

The interannual variation of net primary productivity of three coniferous forests in Liupan Mountains of Ningxia and its responses

to climatic factors

WANG Yunni, XIONG Wei, WANG Yanhui, et al (4002)

Soil water use and balance characteristics in mature forest land profile of Caragana korshinskii in Semiarid Loess Area

MO Baoru, CAI Guojun, YANG Lei,LU Juan, et al (4011)

Effect of simulated acid deposition on chemistry of surface runoff in monsoon evergreen broad-leaved forest in Dinghushan

QIU Qingyan, CHEN Xiaomei, LIANG Guohua, et al (4021)

A space optimization model of water resource conservation forest in Dongting Lake based on improved PSO

LI Jianjun, ZHANG Huiru, LIU Shuai, et al (4031)

Allelopathic effects of aqueous extract of exotic plant Rhus typhina L. on soil micro-ecosystem

HOU Yuping, LIU Lin, WANG Xin, et al (4041)

The impact of natural succession process on waterbird community in a abandoned fishpond at Chongming Dongtan, China

YANG Xiaoting, NIU Junying, LUO Zukui, et al (4050)

Mercury contents in fish and its biomagnification in the food web in Three Gorges Reservoir after 175m impoundment

YU Yang, WANG Yuchun, ZHOU Huaidong, et al (4059) 
Microsatellite analysis on genetic diversity of common carp, Cyprinus carpio, populations in Yuan River

YUE Xingjian, ZOU Yuanchao, WANG Yongming, et al (4068)

\section{Landscape, Regional and Global Ecology}

Research on spatio-temporal change of temperature in the Northwest Arid Area HUANG Rui, XU Ligang, LIU Junmin (4078)

Simulation of soil respiration in forests at the catchment scale in the eastern part of northeast China

GUO Lijuan, GUO Qingxi (4090)

The early effects of nitrogen addition on $\mathrm{CH}_{4}$ uptake in an alpine meadow soil on the Eastern Qinghai-Tibetan Plateau

ZHANG Peilei, FANG Huajun, CHENG Shulan, et al (4101)

Analysis of water ecological footprint in guangxi based on ecosystem services ZHANG Yi, ZHANG Heping (4111)

The integrated recognition of the source area of the urban ecological security pattern in Shenzhen

WU Jiansheng, ZHANG Liqing, PENG Jianet al (4125)

Carbon sources and storage sinks in scenic tourist areas: a Mount Lushan case study

ZHOU Nianxing, HUANG Zhenfang, LIANG Yanyan (4134)

Impacts of climate change on dominant pasture growing season in Central Inner Mongolia

LI Xiazi, HAN Guodong, GUO Chunyan (4146)

Phenological Characteristics of Typical Herbaceous Plants (Lris lacteal) and Its Response to Climate Change in Minqin Desert

HAN Fugui, XU Xianying, WANG Lide, et al (4156)

Biomass and distribution pattern of carbon storage in Eomecon chionantha Hance

TIAN Dalun, YAN Wende, LIANG Xiaocui, et al (4165)

Temporal dynamics and influencing factors of fine roots in five Chinese temperate forest ecosystems

LI Xiangfei, WANG Chuankuan, QUAN Xiankui (4172)

\section{Resource and Industrial Ecology}

Effects of AMF on soil improvement and maize growth in mining area under drought stress

LI Shaopeng, BI Yinli, CHEN Peizhen, et al (4181)

\section{Urban, Rural and Social Ecology}

Health function evaluation and exploring its mechanisms in the Shanghai Green Belt, China

ZHANG Kaixuan, ZHANG Jianhua (4189)

\section{Research Notes}

Time lag effects of rainfall inside a Platycladus Orientalis plantation forest in the Beijing Mountain Area, China

SHI Yu, YU Xinxiao,ZHANG Jiayin (4199)

Long-term effects of harvest residue management on soil total carbon and nitrogen concentrations of a replanted Chinese fir 


\section{《生态学报》2013 年征订启事}

《生态学报》是由中国科学技术协会主管, 中国生态学学会、中国科学院生态环境研究中心主办的生态学 高级专业学术期刊,创刊于 1981 年,报道生态学领域前沿理论和原始创新性研究成果。坚持“百花齐放,百家 争鸣” 的方针, 依靠和团结广大生态学科研工作者, 探索生态学奥秘, 为生态学基础理论研究搭建交流平台, 促进生态学研究深人发展, 为我国培养和造就生态学科研人才和知识创新服务、为国民经济建设和发展服务。

《生态学报》主要报道生态学及各分支学科的重要基础理论和应用研究的原始创新性科研成果。特别欢 迎能反映现代生态学发展方向的优秀综述性文章; 研究简报; 生态学新理论、新方法、新技术介绍; 新书评价和 学术、科研动态及开放实验室介绍等。

《生态学报》为半月刊,大 16 开本,300 页,国内定价 90 元/册,全年定价 2160 元。

国内邮发代号:82-7, 国外邮发代号:M670

标准刊号: ISSN 1000-0933 CN 11-2031/Q

全国各地邮局均可订阅,也可直接与编辑部联系购买。欢迎广大科技工作者、科研单位、高等院校、图书 馆等订阅。

通讯地址: 100085 北京海淀区双清路 18 号 电 话: (010)62941099; 62843362

E-mail: shengtaixuebao@ rcees. ac. cn 网址: www. ecologica.cn

本期责任副主编 彭少麟编辑部主任 孔红梅执行编辑 刘天星 段 靖

生 态 学 报

( SHENGTAI XUEBAO)

(半月刊 1981 年 3 月创刊)

第 33 卷第 13 期 (2013 年 7 月)

\section{ACTA ECOLOGICA SINICA}

(Semimonthly, Started in 1981)

Vol. 33 No. 13 (July, 2013)

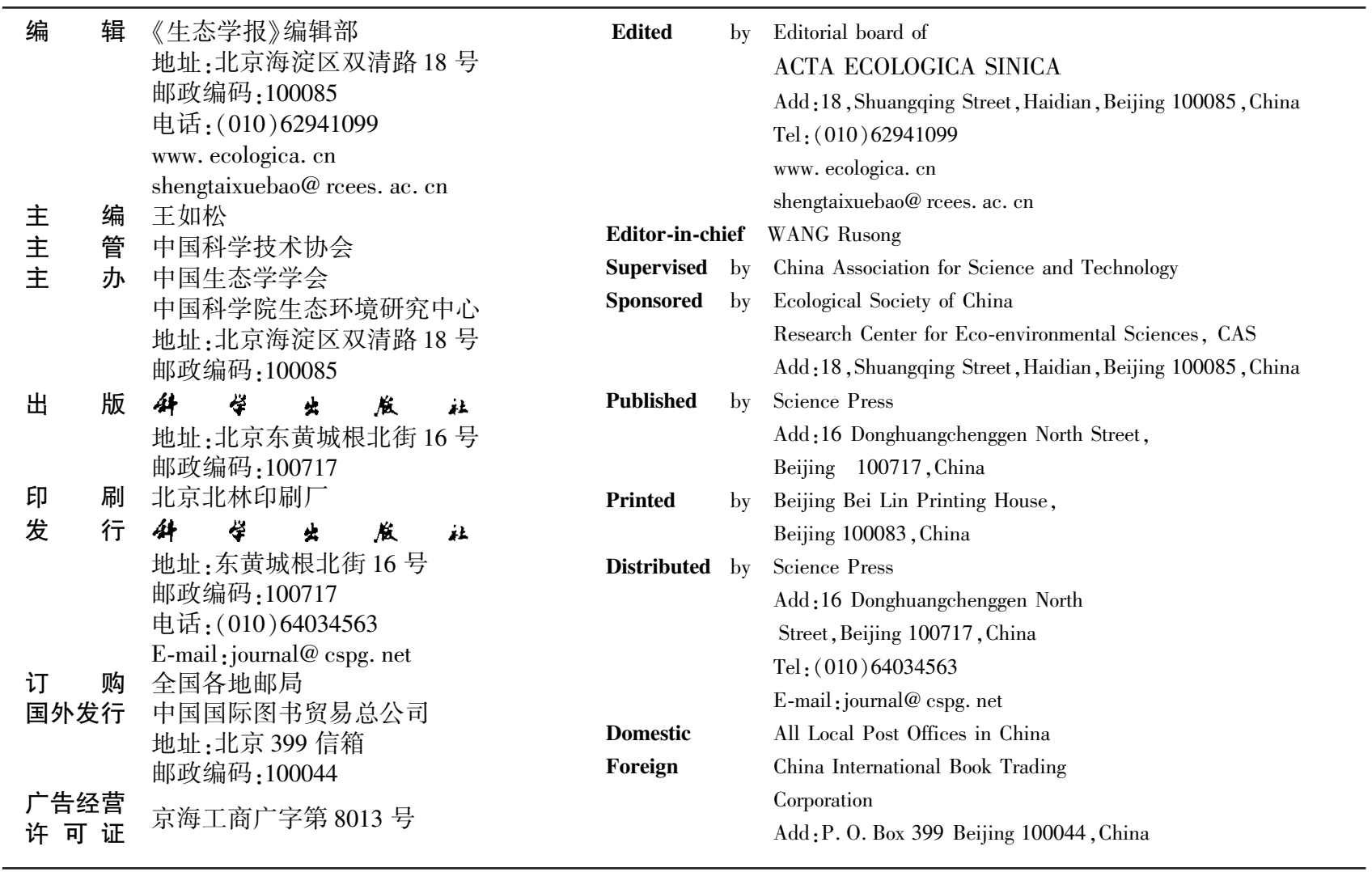

ISSN 1000-0933

CN $11-2031 / Q$

国内外公开发行

国内邮发代号 82-7

国外发行代号 M670

定价 90.00 元 